\title{
THE COMPARISON OF TREE QUALITIES ${ }^{1}$
}

\author{
BY P. L. NORTHCOT ${ }^{2}$
}

\section{ABSTRACT}

The need to compare individuals is discussed briefly. It is suggested that the composite quality of an individual is best defined as the weighted sum of a number of measurable characteristics of the individual. A statistical procedure for comparison of weighted average quality is derived from application of the principle of the linear combination of variables. A digital computer program is available.

\section{INTRODUCTION}

It is frequently necessary to compare individuals, such as trees, that are not readily described by a single characteristic. If we describe a tree by any single variable, say its height, we lose the value of the other variables or attributes, such as its volume, freedom from limbs, strength, etc., that also describe it: similarly for any other single measurable characteristic. Clearly, if we are to compare two trees objectively we must find a method for combining several of these measurable characteristics that describe the trees. Furthermore, the list of important factors may be different for each use to which the tree might be put. For example, the characteristics that make a tree desirable for decorative veneers would include uniqueness and beauty of the wood and its peeling or slicing properties, while the desirability of a tree for pulp and paper would include the ease with which it can be chipped and pulped, the dimensions of the wood cells, and the colour of the resulting pulp and paper, and many other characteristics. Also, for a specific use, each of the important characteristics may have a different importance (weight) for that use. For example, the dimensions of the wood cells may be more important than the ease of pulping. An additional problem is that each of these important variables may be measured on a different scale such as feet, cubic feet, pounds per cubic foot, pounds per square inch, etc.

If, for the purpose of this paper, we define the combination of measurable characteristics of a tree that combine to make it especially useful for a specified purpose as the quality of the tree for that purpose, then the general question to which we address ourselves is "How can we objectively measure the quality of a tree?" Then we will be interested in the question "How can we objectively compare the qualities of two or more trees?"'

\footnotetext{
${ }^{1}$ Department of Forestry of Canada, Forest Products Research Branch, Contribution Number P-104.

- Research Officer, Vancouver Laboratory, F.P.R.B.
} 
To illustrate, take a look at the results of the numerical example that concludes this article. In the example, basal area, spiral grain, specific gravity, and tracheid length are given different weights and, after appropriate transformation, added together to provide an estimate of the combined worth of the tree for some particular use, say, for pulp and paper. The (dimensionless) quality values for the two trees of the example are $\bar{Q}_{A}=10.175$ and $\bar{Q}_{B}=7.824$, the corresponding variances $S^{2}=.02734$ and $S^{2}=0.02912$, and degrees of freedom 9 and 10. A " $t$ " test for the significance of the difference between the means:

$$
\mathrm{t}=\left(\overline{\mathrm{Q}}_{\mathrm{A}}-\overline{\mathrm{Q}}_{\mathrm{B}}\right) / \sqrt{\mathrm{S}_{\overline{\mathrm{Q}}_{\mathrm{A}}}+\mathrm{S}^{2}} \overline{\mathrm{Q}}_{\mathrm{B}}=(10.175-7.824) / \sqrt{0.02734+0.02912}
$$

$=9.895$ with $9+10=19$ degrees of freedom, is highly significant $(\mathbf{P}=$ 0.001 level). Therefore, with one chance in a thousand of being wrong, it can be taken that Tree A is superior to Tree B (on the basis of the chosen characteristics, weights, sampling system, etc.). Surely this is the kind of answer that is required when comparing any two complex organisms or populations thereof.

\section{Methods}

Three methods for comparing qualities are: the intuitive, the rejection, and the additive methods.

The intuitive approach relies upon the ability of each person to subconsciously integrate the many characteristics that constitute the quality of the tree for a specified use into an overall assessment. The process must then be extended to the ranking of the available trees. Whatever the merit of the system, no practical way exists to obtain absolute reproducibility from person to person.

In the rejection method, the individuals are, in principle, first measured for one characteristic $\left(X_{1}\right)$, say height, and either accepted or rejected on the basis of some predetermined maximum or minimum value. Those rejected for $X_{1}$ are eliminated from further consideration regardless of their excellence in the remaining characteristics. Those accepted for $X_{1}$ are then subjected to a similar process and either accepted or rejected for $X_{2}$. This process is repeated through all of the X's. However, while this method would reduce the number of candidates, it can only classify, them as acceptable or not acceptable, and fails to arrange them in any order of superiority.

There are at least two versions of the additive method. One used by Nicholls and Dadswell (1961) is based upon the following principle: first rank the trees for each of the X's, then add the ranks across the X's for each tree to obtain a total score for that tree, and then use the ranks of the totals as the measure of tree quality. Another variation of this method is attributed to Haggstrom (1964). A major objection to the system is the lack of a measure of the imprecision associated with each estimate of quality.

This difficulty is overcome in the second additive approach, which is based upon the statistical principle: the linear combination of variables (Uspensky, 1937; Hogg and Craig, 1959). The basic problem is how to obtain a weighted average quality complete with confidence limits. 
As an example, suppose that we have two trees, $A$ and $B$, with average qualities $\bar{Q}_{A}$ and $\bar{Q}_{B}$ and we wish to decide which of the two should be used in a seed orchard-the progeny to be grown to produce pulp and paper. For the purpose of this example, let us assume that the important measurable characteristics are:

$$
\begin{aligned}
& \mathrm{X}_{1}=\text { the area circumscribed by the } 10 \text { th to } 35 \text { th rings } \\
& \text { from the pith at breast height, in sq. } \mathrm{cm} \text {., } \\
& \mathrm{X}_{2}=\text { weighted average spiral grain in degrees, } \\
& \mathrm{X}_{3}=\text { weighted average specific gravity (a ratio), } \\
& \mathrm{X}_{4}=\text { weighted average tracheid length in mm., } \\
& \mathrm{X}_{5}=\text { deviations from straightness of the stem in } \mathrm{mm} . / \text { metre, } \\
& \mathrm{X}_{\mathrm{n}}=\text { percentage of volume occupied by knots. }
\end{aligned}
$$

Let us assume that all are normally distributed random variables with population means $\mu_{1}, \mu_{2}, \ldots \mu_{\mathrm{n}}$, population variances $\sigma_{1}{ }^{2}, \sigma_{2}{ }^{2}, \ldots \sigma_{\mathrm{n}}{ }^{2}$, and population simple correlation coefficients $\tau_{12}, \tau_{13}, \tau_{23}, \ldots \tau_{(\mathrm{n}-1) \mathrm{n}}$. Suppose that $\overline{\mathrm{X}}_{1}, \overline{\mathrm{X}}_{2}$, $\ldots \mathrm{X}_{\mathrm{n}}$ are the corresponding sample means and $\mathrm{S}_{1}{ }^{2}, \mathrm{~S}_{2}{ }^{2}, \ldots \mathrm{S}_{\mathrm{n}}{ }^{2}$ the corresponding mean square estimators of $\sigma_{1}^{2}, \sigma_{2}^{2}, \ldots \sigma_{n 1}^{2}$ calculated from $p_{1}, p_{2}$, $\ldots p_{n}$ specimens per sample and with $f_{1}, f_{2}, \ldots f_{n}$ degrees of freedom. Let $r_{12}, r_{13}, r_{23}, \ldots r_{(n-1) n}$ be the simple correlation coefficients calculated from the sample. Let us assume:

(1) that a scale of measurement is available for each of the X's as well as the necessary equipment and techniques for measuring each, (2) a suitable sampling unit and method is available, and (3) the relative importance of the X's is known from previous economic analysis and is given, respectively for $X_{1}, X_{2}$, $\ldots \mathrm{X}_{\mathrm{n}}$ by the constants (weights) $\mathrm{k}_{1}, \mathrm{k}_{2}, \ldots \mathrm{k}_{\mathrm{n}}$.

It is essential that these $X$ 's be additive in the sense that an increasing value of $\mathrm{X}_{1}$ increases the tree quality and similarly for $\mathrm{X}_{2}, \mathrm{X}_{3}, \ldots \mathrm{X}_{\mathrm{n}}$. Should the opposite be true for a particular $X$, say $X_{2}$, then it will be necessary to either subtract instead of add it, or transform the values of $X_{2}$, say by calculating the reciprocal, to correct this situation. This situation arises with $X_{2}$ in the numerical sample at the end of the paper.

With this background, we can now look at the problem of how to measure objectively the quality of a tree. We require a method for calculating the weighted-average quality of the tree and its variance or standard deviation. With this information for two (or more) trees we will be in a position to compare the qualities of the trees statistically. The starting point is to define the weighted linear combination of variables:

$$
\begin{aligned}
& \mathrm{Y}=\left(\mathrm{k}_{1} / \Sigma \mathrm{k}\right) \mathrm{X}_{1}+\left(\mathrm{k}_{2} / \Sigma \mathrm{k}\right) \mathrm{X}_{2}+. \dot{ }+\left(\mathrm{k}_{\mathrm{n}} / \Sigma \mathrm{k}\right) \mathrm{X}_{\mathrm{n}} \\
& \text { where } \Sigma \mathrm{k} \text { is the sum of the } \mathrm{k}^{\prime} \mathrm{s} \text {, so that }\left(\mathrm{k}_{1}+\mathrm{k}_{2}+\ldots+\mathrm{k}_{\mathrm{n}}\right) / \Sigma \mathrm{k}=1 \text {. }
\end{aligned}
$$

We then have the mean of $\mathrm{Y}$ :

$$
\mu_{\mathrm{Y}}=\left(\mathrm{k}_{1} / \Sigma \mathrm{k}\right) \mu_{1}+\left(\mathrm{k}_{2} / \Sigma \mathrm{k}\right) \mu_{2}+\ldots+\left(\mathrm{k}_{\mathrm{n}} / \Sigma \mathrm{k}\right) \mu_{\mathrm{n}}
$$

We also have the variance of $\mathrm{Y}$ : (not the variance of $\mu_{\mathrm{Y}}$ ):

$$
\sigma_{\mathrm{Y}}^{2}=\left(\mathrm{k}_{1} / \Sigma \mathrm{k}\right)^{2} \sigma_{1}^{2}+\left(\mathrm{k}_{2} / \Sigma \mathrm{k}\right)^{2} \sigma_{2}^{2}+\ldots .+\left(\mathrm{k}_{\mathrm{n}} / \Sigma \mathrm{k}\right) \sigma_{\mathrm{n}}{ }^{2}+
$$

$2 \mathrm{k}_{1} \mathrm{k}_{2} \tau_{12} \sigma_{1} \sigma_{2} /(\Sigma \mathrm{k})^{2}+\ldots 2 \mathrm{k}_{(\mathrm{n}-1)} \mathrm{k}_{\mathrm{n}} \tau_{(\mathrm{n}-1) \mathrm{n}} \sigma_{(\mathrm{n}-1)} \sigma_{\mathrm{n}} /(\Sigma \mathrm{k})^{2}$

In the special case where the X's are independent, equation (3) simplifies to:

$$
\sigma_{\mathrm{Y}}^{2}=\left(\mathrm{k}_{1} / \Sigma \mathrm{k}\right)^{2} \sigma_{1}^{2}+\left(\mathrm{k}_{2} / \Sigma \mathrm{k}\right) \sigma_{2}^{2}+\ldots+\left(\mathrm{k}_{\mathrm{n}} / \Sigma \mathrm{k}\right)^{2} \sigma_{\mathrm{D}}^{2} \ldots
$$


In our example, $X_{1}, X_{2}, \ldots X_{n}$ all have different scales of measurement. These constitute an additional, undesirable, weighting factor. To avoid this difficulty, reduce each of the X's to the same dimensionless state by dividing it by the standard deviation calculated from the sample, thus: $\left(X_{1} / S_{1}\right)$, $\left(X_{2} / S_{2}\right), \ldots\left(X_{n} / S_{n}\right)$ with corresponding sample variances $\left(S_{1}^{2} / S_{1}^{2}\right)=1$, $\left(\mathrm{S}_{2}{ }^{2} / \mathrm{S}_{2}{ }^{2}\right)=1, \ldots\left(\mathrm{S}_{\mathrm{n}}{ }^{2} / \mathrm{S}_{\mathrm{n}}{ }^{2}\right)=1$. When two or more trees are to be compared, the correct values of $S_{1}, S_{2}, \ldots S_{n}$, which must be used for each of the trees involved in the comparison, are calculated from the pooled mean squares of the two or more trees, i.e.

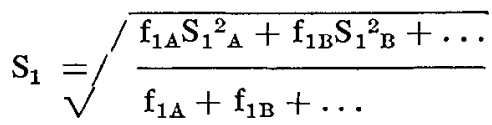

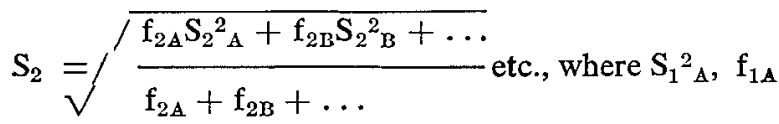

are the variance and degrees of freedom for Factor $X_{1}$ and Tree $A ; S_{1}{ }_{B}, f_{1 B}$ are the corresponding values for Factor $X_{1}$ and Tree $B ; S_{2}{ }_{A}, f_{2 A}$ are the corresponding values for Factor $\mathrm{X}_{2}$ and Tree $\mathrm{A}$, etc. This pooling of variances over the trees to be compared is necessary if another undesirable weighting factor is to be avoided.

Generally, in experimental work, instead of relying upon a single measurement of a characteristic of a specimen it is customary to increase the accuracy by taking more than one measurement and calculating the average. On the assumption that this will be done, substitute for $\left(X_{1} / S_{1}\right),\left(X_{2} / S_{2}\right)$. . . $\left(\mathrm{X}_{\mathrm{n}} / \mathrm{S}_{\mathrm{n}}\right)$, the sample means $\left(\overline{\mathrm{X}}_{1} / \mathrm{S}_{1}\right)\left(\overline{\mathrm{X}}_{2} / \mathrm{S}_{2}\right) \ldots\left(\overline{\mathrm{X}}_{\mathrm{n}} / \mathrm{S}_{\mathrm{n}}\right)$ of $\mathrm{p}_{1}, \mathrm{p}_{2}, \ldots \mathrm{p}_{\mathrm{n}}$ specimens. The variances of these means will be $S^{2} / p$ which, in this case will be, respectively $1 / \mathrm{p}_{1}, 1 / \mathrm{p}_{2}, \ldots 1 / \mathrm{p}_{\mathrm{n}}$, with $\left(\mathrm{p}_{1}-1\right),\left(\mathrm{p}_{2}-1\right), \ldots\left(\mathrm{p}_{\mathrm{n}}-1\right)$ degrees of freedom.

If, now, we substitute $\overline{\mathrm{Q}}$ for $\mu_{\mathrm{y}}$ and ( $\overline{\mathrm{X}} / \mathrm{S}$ )'s for $\mu$ 's in equation (2) we obtain the (dimensionless, weighted, mean) quality of the tree:

$\overline{\mathrm{Q}}=\left(\mathrm{k}_{1} / \Sigma \mathrm{k}\right)\left(\overline{\mathrm{X}}_{1} / \mathrm{S}_{1}\right)+\left(\mathrm{k}_{2} / \Sigma \mathrm{k}\right)\left(\overline{\mathrm{X}}_{2} / \mathrm{S}_{2}\right) \ldots+\left(\mathrm{k}_{\mathrm{n}} / \Sigma \mathrm{k}\right)\left(\overline{\mathrm{X}}_{\mathrm{n}} / \mathrm{S}_{\mathrm{n}}\right) \ldots$

Substituting the variance of the mean quality, $S^{2}$, for the variance of the $\bar{Q}$

population, $\sigma_{\mathrm{Y}}{ }^{2}$, and the variances of the $(\overline{\mathrm{X}} / \mathrm{S})$ 's; i.e. $1 / \mathrm{p}_{1}, 1 / \mathrm{p}_{2}, \ldots 1 / \mathrm{p}_{\mathrm{n}}$ for the population variances $\sigma_{1}{ }^{2}, \sigma_{2}{ }^{2}, \ldots \sigma_{n}{ }^{2}$, in equation (3), we obtain the variance of $\bar{Q}$ :

$$
\begin{aligned}
\mathrm{S}_{\overline{\mathrm{Q}}}^{2}= & \left(\mathrm{k}_{1} / \Sigma \mathrm{k}\right)^{2}\left(1 / \mathrm{p}_{1}\right)+\left(\mathrm{k}_{2} / \Sigma \mathrm{k}\right)^{2}\left(1 / \mathrm{p}_{2}\right)+\ldots+\left(\mathrm{k}_{\mathrm{n}} / \Sigma \mathrm{k}\right)^{2}\left(1 / \mathrm{p}_{\mathrm{n}}\right)+ \\
& +\frac{2 \mathrm{k}_{1} \mathrm{k}_{2} \mathrm{r}_{12} 1 / \mathrm{p}_{1} \mathrm{p}_{2}+\ldots}{(\Sigma \mathrm{k})^{2}}+\frac{2 \mathrm{k}_{(\mathrm{n}-1)} \mathrm{k}_{\mathrm{n}} \mathrm{r}(\mathrm{n}-1) \mathrm{n} 1 / \mathrm{p}_{(\mathrm{n}-1)} \mathrm{p}_{\mathrm{n}}}{(\Sigma \mathrm{k})^{2}}
\end{aligned}
$$


The suggested degrees of freedom ${ }^{3}$ are:

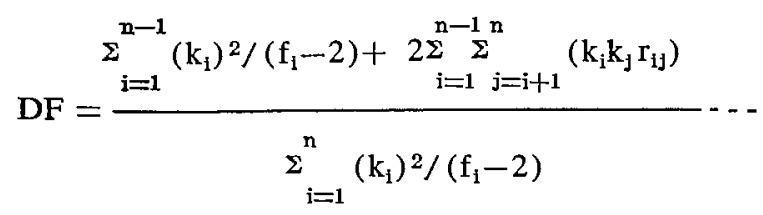

where $\mathrm{i}+1 \leqq \mathrm{j} \leqq$ n, i.e. the cross-product terms are summed over all of the values of $i$ and $j$ with $i$ less than $j$ that are different from each other.

In case the significances are marginal it is permissible to compute degrees of freedom to one or two decimals and interpolate in the " $t$ " or " $F$ " tables.

The tree quality is presented in equation (5), its variance in equation (6), and degrees of freedom in equation (7). If we obtain this information for two or more trees we can compare them by calculating confidence limits, or " $\mathrm{t}$ " values, or the resulting qualities can be used, with appropriate independent variables, in analyses of variance, covariance, regression or correlation. A computer program for the necessary calculations is available through $\mathrm{Dr}$. A. Kozak. ${ }^{4}$ The procedure for comparing the mean quality of two trees $\overline{Q_{A}}$ and $\overline{\mathrm{Q}_{\mathrm{B}}}$ is illustrated with the following numerical example, using the first four (dependant) variables discussed earlier and ignoring variables 5 to $\mathrm{n}$ by assuming that variable $\mathrm{X}_{5}$ has identical values for both trees, and similarly for $\mathrm{X}_{6}, \mathrm{X}_{7} \ldots \mathrm{X}_{\mathrm{n}}$.

\section{Numerical EXAMPLE}

The means, standard deviations, and number of samples from which these wer were calculated, for each of four measurable characteristics $\left(\mathrm{X}_{1}, \mathrm{X}_{2}, \mathrm{X}_{3}\right.$, and in $\mathrm{X}_{4}$ ), are resented in Table 1 for each of two trees. Also included, in the last column, are the standard deviations calculated from the pooled variances of the two trees. In Table 2 are listed the simple correlation coefficients indicating the degree of correlation between the four variables.

In Table 3 are listed the weights (k's) assigned to the different $X$ 's, the dimensionless means (X/S's), the variances of the means (1/p's), and associated degrees of freedom, for each of the four X's, for each of the two trees.

The weights (k's) assigned to the different X's for this example are not to be construed as the most economic for any chosen use.

Substituting the appropriate information from these tables in Equation 5, we get the dimensionless, weighted, mean quality for each tree.

$$
\begin{aligned}
\overline{Q_{\Delta}}= & (1.5 / 6.5)(21.033) \\
& (1.0 / 6.5)(15.498)=10.176, \text { and }
\end{aligned}=\underset{(2.0 / 6.5)(1.084)}{(10 / 6.5)(10.646)+}+
$$

\footnotetext{
${ }^{3}$ Degrees of freedom suggested by Dr. S. W. Nash, Professor of Mathematics, University of British Columbia.

‘Dr. A. Kozak, Research Officer, Vancouver Laboratory, FPRB, Department of Forestry, Government of Canada. The program is available in Fortran IV.
} 


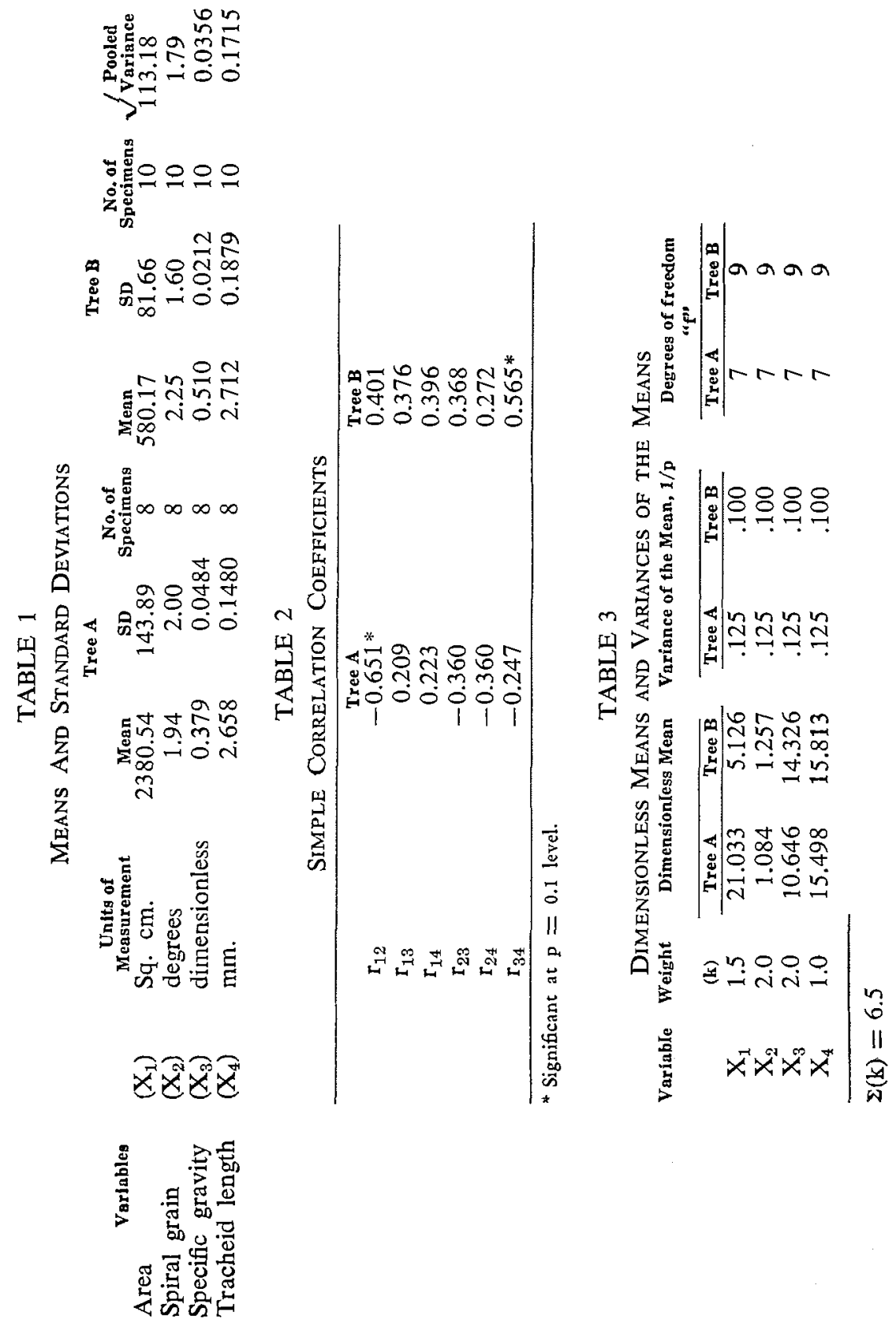


$\overline{\mathrm{Q}}_{\mathrm{B}}=(1.5 / 6.5)(5.126)-(2.0 / 6.5)(1.257)+(2.0 / 6.5)(14.326)+$ $(1.0 / 6.5)(15.813)=7.824$.

Substituting the appropriate information in Equation 6, we get the variances for the mean quality of each tree.

$$
\begin{aligned}
& \mathrm{S}^{2}=(1.5 / 6.5)^{2}(0.125)+(2.0 / 6.5)^{2}(0.125)+(2.0 / 6.5)^{2}(0.125)+ \\
& \overline{\mathrm{Q}}_{\mathrm{A}} \\
& \quad(1.0 / 6.5)^{2}(0.125)-2(1.5 / 6.5)(2.0 / 6.5)(0.651)(\sqrt{(0.125)(0.125))} \\
& \quad=0.02734 \\
& \mathrm{~S}^{2}=(1.5 / 6.5)^{2}(0.100)+(2.0 / 6.5)^{2}(0.100)+(2.0 / 6.5)^{2}(0.100)+ \\
& \overline{\mathrm{Q}}_{\mathrm{B}} \\
& \quad(1.0 / 6.5)^{2}(0.100)+2(2.0 / 6.5)(1.0 / 6.5)(0.565)(\sqrt{(0.100)}(0.100)) \\
& \quad=0.02912
\end{aligned}
$$

It will be noted that only one of the six possible cross-product terms has been included in the calculation of each of these veriances. In the variance of Tree $A$ the cross-product involving $r_{12}=-0.651$ is included because of the significant correlation (at the $\mathrm{p}=0.1$ level) between $\mathrm{X}_{1}$ and $\mathrm{X}_{2}$. The other five cross-products have not been included because, the $r-$ values being non-significant, the X's are assumed to be independent, and therefore make zero contribution to the variance. Similarly in the case of Tree B, except the correlated X's are $\mathrm{X}_{3}$ and $\mathrm{X}_{4}$.

Substituting the appropriate values in Equation 7, we get the following degrees of freedom:

$$
\begin{aligned}
& \mathrm{DF}_{\mathrm{A}}=8.725 \text { which is approximately 9, } \\
& \mathrm{DF}_{\mathrm{B}}=10.397 \text { which is approximately } 10 .
\end{aligned}
$$

Applying a " $t$ " test to the differences of the means, we have

$$
\mathrm{t}=\left(\overline{\mathrm{Q}}_{\mathrm{A}}-\overline{\mathrm{Q}}_{\mathrm{B}}\right) / \sqrt{\mathrm{S}^{2}+\mathrm{S}^{2}}=(10.175-7.824) / \sqrt{0.02734+0.2912}
$$

$=9.895$ with $9+10=19$ degrees of freedom, which is significant at the $\mathrm{p}=0.001$ level. Therefore, with one chance in a thousand of being wrong, we can state that, as defined, the (dimensionless, weighted, mean) quality of Tree $A$ is superior to that of Tree $B$.

\section{BIBLIOGRAPHY}

HAGGSTROM, B. 1964. Directions for Evaluating and Selecting Plus Trees. Unasylva, Vol. 18 (2-3), No. 73-74, P. 128 .

HOGG and CRAIG. 1959. Introduction to Mathematical Statistics. P. 51

NICHOLLS, J. W. P. and H. E. DADSWELL. 1961. Assessment of Wood Qualities for Treo Breeding in Pinus pinaster Ait. from South Australia, CSIRO. Division of Forest Products, South Melbourne, Australia.

USPENSKY, J. V. 1937. Introduction to Mathematical Probability. McGraw Hill. P. 174. 